\title{
The IAU C41 Working Groups and their contribution to international history of astronomy research
}

\author{
Wayne Orchiston \\ Centre for Astrophysics, University of Southern Queensland, \\ Toowoomba, Queensland 4350, Australia \\ email: wayne.orchiston@gmail.com
}

\begin{abstract}
IAU Commission 41 (History of Astronomy) was founded in 1948, and between 1991 and its termination in 2015 this Commission hosted seven different Working Groups (one of which was shared with Commission 40 (Radio Astronomy). In this paper we list the objectives of these seven Working Groups and track their progress. We conclude by evaluating the role that each C41 Working Group played in furthering research on the history of astronomy.
\end{abstract}

Keywords. IAU Commission C41 (History of Astronomy), working groups, archives, astronomical chronology, astronomy and World Heritage, historic radio-astronomy, historical instruments, Johannes Kepler, transits of Venus

\section{Introduction}

At the VIIth General Assembly (henceforth GA) of the IAU in Zürich in 1948 an unusual new commission was formed. Unlike other commissions that were primarily observationally-based, C41 was devoted to the history of astronomy, and was the brain child of UNESCO's International Union of History of Science (Kochhar et al. 2015) which was keen to see historical commissions launched in various international scientific unions. But as Ruggles et al. (2011) have pointed out, the early years of the Commission were rocky:

"... Otto Neugebauer was appointed the first President in his absence, but proceeded to express his conviction that 'an international organization in the history of astronomy has no positive function ... my only activity during my term of service consisted in iterated attempts to resign'..."

Despite an initial membership of less than twenty (Débarbat 2002) and Neugebauer's convictions, the Commission survived, and "...quickly assumed a key role in the international development of the history of astronomy as an academic discipline" (Ruggles et al. 2011).

In 1991 the first C41 Working Group (henceforth WG) was formed, and over the next two decades - prior to the Hawaiian General Assembly in 2015 - six more WGs were founded. These are listed below in Table 1, and our aim in this paper is to examine the history of each and the extent to which each WG contributed to international history of astronomy research.

\section{The C41 Working Groups}

\subsection{Archives}

Suzanne Débarbat (Débarbat 2002) has provided an excellent review of the early history of the Archives WG. Apparently, astronomical archives were first mentioned at a 
Table 1. IAU C41 Working Groups formed between 1991 and 2009

\begin{tabular}{|c|c|c|c|}
\hline Name & Founded & $\begin{array}{l}\text { Chairpersons, up to } 2014 \\
\text { (in chronological order) }\end{array}$ & Comments \\
\hline Archives & 1991 & Débarbat, Corbin, Chinnici & \\
\hline Astronomical Chronology & 2000 & Gurshtein & \\
\hline Historical Instruments & 2000 & Nha, Pigatto, Schechner & \\
\hline Transits of Venus & 2000 & $\begin{array}{l}\text { Orchiston, Dick, Duerbeck, } \\
\text { Orchiston }\end{array}$ & $\begin{array}{l}\text { To be terminated after } \\
\text { the } 2012 \text { transit }\end{array}$ \\
\hline Historic Radio Astronomy & 2003 & $\begin{array}{l}\text { Orchiston, Kellermann, } \\
\text { Wielebinski }\end{array}$ & From 2015 solely a B4 WG \\
\hline Astronomy and World Heritage & 2008 & Ruggles & $\begin{array}{l}\text { At the } 2015 \text { GA became } \\
\text { Commission C4 }\end{array}$ \\
\hline Johannes Kepler & 2009 & Mahoney & $\begin{array}{l}\text { After } 2015 \text { continued as a } \\
\text { C3 WG }\end{array}$ \\
\hline
\end{tabular}

C41 meeting at the 1958 GA in Moscow, and there were follow-up discussions at the 1961 and 1964 GAs (in Berkeley and Hamburg) and an archives resolution was passed at the 1967 GA in Prague. Débarbat (2002) notes that the 1970s and 1980s were growth years for $\mathrm{C} 41$, and at various times the preservation and copying of astronomical archives were discussed, but "Another important development was the founding of the Journal for the History of Astronomy in 1970, and almost from the start descriptions of important astronomical archives features in its pages" (ibid.).

Following discussions at the $1988 \mathrm{GA}$ in Baltimore, IAU Commissions 5 (Documentation and Astronomical Data) and 41 proposed the following C4 resolution on Astronomical Archives at the 1991 IAU GA in Buenos Aires:

(a) to establish a register of the whereabouts of all extant astronomical archives of historical interest;

(b) to impress on observatories and other institutions their responsibility for the preservation, conservation, and where possible, cataloguing of such archives;

(c) to search for an institution that will allocate space and funds for maintaining such a register and publishing it (Débarbat 2002).

This resolution was endorsed by the GA and C41's first WG was formed (shared with Commission 5). The inaugural Chairperson was Paris Observatory's Dr Suzanne Débarbat (Fig. 1) who at the time was President of C41, so was in an ideal position to lead the new WG.

Débarbat (2002) notes that

"The first objective was to stop the wholesale destruction of material of historical value, and the second objective was to make the whereabouts of such material better known to scholars. Many instances were reported ... of situations where directors of institutes, librarians, and others invested great care in the preservation of materials over a long time intervals [sic], only to be followed by others who were entirely without feeling for the past and were prepared to sell or destroy our astronomical heritage."

Perhaps most challenging - in that it would involve a long-term co-ordinated international effort - was the first of these resolution objectives, and the WG's strategy was to begin by encouraging colleagues "... to build up national inventories of astronomical archives in different countries, and to document, research and disseminate information on individual archives, and on individual archival records." (Débarbat 2002). Members of the Organising Committee (henceforth OC) of the new WG were from England, France, Italy, Switzerland and the USA, and they reported at the 1994 GA in The Hague. This GA also featured a Joint Discussion celebrating Seventy-five Years of the IAU and the 


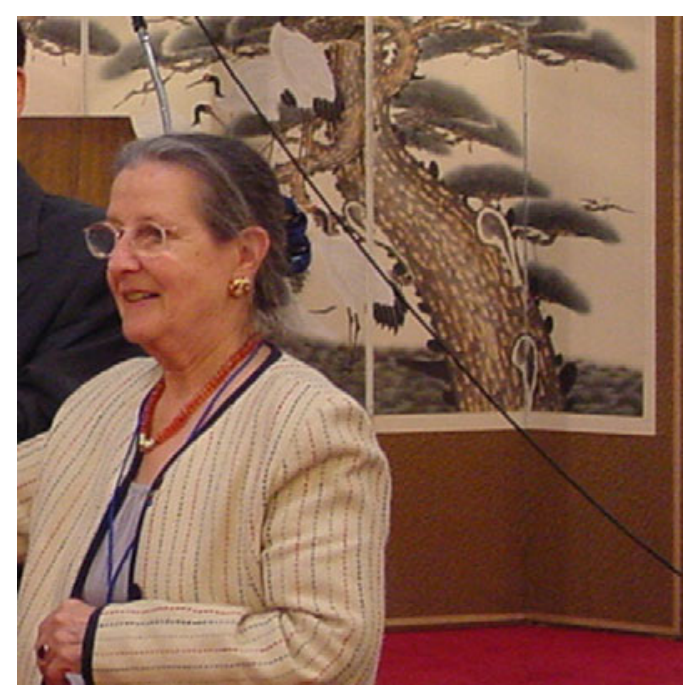

Figure 1. Founding Chairperson of the C41 Archives Working Group, Suzanne Débarbat, attending a conference in South Korea in 2002 (photograph: Wayne Orchiston).

publication of Professor Adriaan Blaauw's book History of the IAU: The Birth and First Half-Century of the International Astronomical Union (Blaauw 1994), both of which endorsed the importance of astronomical archives.

Despite this, the WG was largely inactive between 1994 and 2000, because one of the purposes of running a Special Session on Inventory and Preservation of Astronomical Archives, Records and Artifacts at the Manchester GA in 2000

"... was to serve as input to the Working Group on Archives reactivated at this meeting ... by gaining insight into what is being done in individual countries, where progress is being made thanks to individual and institutional efforts. At the same time the session was part of an initiative by the International Union of History and Philosophy of Science to encourage preservation and inventory of scientific archives in general" (Dick \& Orchiston 2000).

At this GA the WG was re-activated, and Dr Débarbat's continuation as its Chairperson was confirmed (Dick \& Orchiston 2000). In 2002 further astronomers (including the author of this paper) were added to the OC of the WG.

In order to provide further opportunities for those in the C41 Archives and Historical Instruments WGs to discuss their work, C41 stalwarts Professors Nha Il-Seong and F. Richard Stephenson and Dr Wayne Orchiston organised an IAU conference on astronomical instruments and archives from the Asia-Pacific region that was held in Cheongju, South Korea, in July 2002. This included five papers relating to Australian, Indian and South Korean astronomical archives (for details see Orchiston et al. 2004e, pp. 62-63). All of these papers were published in the conference proceedings (Orchiston et al. 2004a).

The following year the C41 Archives WG ran a half-day meeting at the 2003 IAU GA in Sydney, with papers presented on Australian, English, French, Georgian, Italian, Japanese, Romanian, Scottish and U.S. archives (for details see Orchiston et al. 2004e, p. 62). Subsequently, most of these papers, along with a selection of papers from the 2000 GA Archives Meeting (on Australian, English, German, Indian and New Zealand archives) were published in a 2004 issue of the Journal of Astronomical Data (JAD) dedicated to astronomical archives and historical transits of Venus. The Editors of the $J A D$ subsequently published this special history of astronomy issue of the journal as 
a paperback book (see Sterken \& Duerbeck 2005). In her 2003-2006 Triennial Report, the then-Chairperson of the WG, Brenda Corbin (Corbin 2007) from the U.S. Naval Observatory, expressed "... deep appreciation to the editors for making these papers more widely available via the Journal issue and the book."

The WG also ran an ambitious programme at the 2006 GA in Prague:

"Two sessions of oral papers were presented, several poster papers were shown, and a business meeting was held. Both oral sessions were well attended, and a lively question and comment period followed each paper as time allowed" (ibid.).

After the success of this wide-ranging research strategy by members, during the 20062009 triennium the WG decided to concentrate on just one major project, 'IAU Archives', in order to collect information about IAU archives dating between 1919 and 1922 in the 19 member countries that formed the Union (see Chinnici et al. 2008). This decision was partly inspired by the publication of Professor Blaauw's History of the IAU: The Birth and First Half-Century of the International Astronomical Union, which was researched and written only after Blaauw (1994, p. xvii) had sorted and inventoried the IAU archives housed at the Office of the General Secretary in Paris. But in deciding on this strategy, the WG OC also was mindful of the up-coming IAU Centennial in 2019 .

Results of the endeavour by the C41 Archives WG to expand on Blaauw's excellent start were discussed at a meeting of the WG held at the Rio de Janeiro General Assembly in 2009 when the then-Chairperson of the WG, Italy's Ileana Chinnici and colleagues noted that the WG

"... met with difficulties in contacting people in some countries and/or in obtaining collaboration for the survey work; this could be due to the voluntary nature of this kind of research, which appears as a lengthy task. Therefore, the WG has decided to create some sub-committees, formed by people corresponding with the WG members in the several countries, to stimulate their collaboration. The creation of these sub-committees is ongoing" (Chinnici et al. 2008).

Later, Chinnici et al. (2011) had to admit that

"Unfortunately, the advancement of the work has slowed down and it has been halted in the past triennium. It has been difficult to establish the sub-committees and, in spite of the WG auspices, the collaboration of people involved in archives has been poor."

Latin America was the only area where substantial progress was made, thanks largely to the efforts of Oscar Matsuura, who presented two reports to the WG (Chinnici et al. 2008). Latin American nations there that joined the IAU (in chronological order) were: Mexico (1921), Brazil (1922), Argentina (1927), Chile (1947), Venezuela (1953), Uruguay (1970), Peru (1988), Bolivia (1998) and Cuba (2001).

The Sixth and Seventh International Conferences on Oriental Astronomy offered some relief for WG members and others wishing to look beyond the confines of IAU archives. These conferences were hosted by James Cook University (Australia) and the National Astronomical Observatory of Japan (in Tokyo) and were held from 7 to 11 July 2008 and from 6 to 10 October 2010, respectively. At the Australian conference, papers were presented on al-Sūfi's Book of the Fixed Stars and a South Korean manuscript (see Orchiston et al. 2011). In Tokyo, papers were presented on Persian astronomical archives, a Japanese map of the Moon, South Korean star maps and a Jesuit manuscript about Chinese and Japanese astronomy in the archives of Paris Observatory, and all of these may be found in the conference proceedings (see Nakamura et al. 2011). 


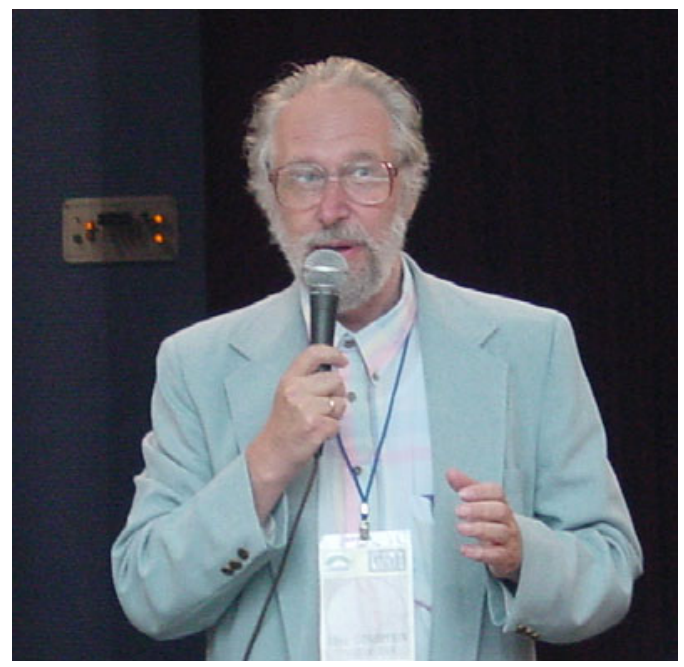

Figure 2. Founding Chairperson of the C41 Astronomical Chronology Working Group, Alexander Gurshtein, speaking at a conference in South Korea in 2002 (photograph: Wayne Orchiston).

Despite ongoing difficulties associated with the IAU Archives project, the WG recognized the importance of this project and decided to continue it during 2009-2012, with the intention of

"...publishing a report as extensive as possible on the conservation of the archival documents concerning the establishment of IAU in all IAU participant countries, a work hopefully to be achieved before the centenary of IAU in 2019" (Chinnici et al. 2011).

Unfortunately, this never came to pass, and in 2014 the WG was closed down and was not re-activated following the Hawaiian General Assembly. Yet during its 23-year lifetime, this WG played a key role in furthering our knowledge of astronomical archives worldwide, and increasing awareness of the historical importance of IAU archives.

\subsection{Astronomical Chronology}

This short-lived WG was formed by the Russian/American astronomer Professor Alexander Gurshtein (Fig. 2) at the 2000 IAU Manchester GA

“... specifically to compile a wide-ranging internationally-approved compendium or text book identifying and documenting the major milestones in the history of astronomy - including key instruments, astronomical phenomena, discoveries and new ideas - that profoundly influenced its development" (Stephenson et al. 2003).

However, from early in its history, members of the WG expressed ". . very serious doubts that such a compendium or a textbook can be compiled in the foreseeable future..." (ibid.), and this is reflected by the lack of any WG annual or triennial reports. By the time the 2006-2009 C41 Report was published by the IAU (see Nha et al. 2008) there is no longer any mention of this WG.

\subsection{Historical Instruments}

When the IAU Archives WG was set up in 1991, there was discussion about whether to include historical instruments within an enlarged WG, but wisely it was decided to defer such a move until progress had been made with the archives initiative. 


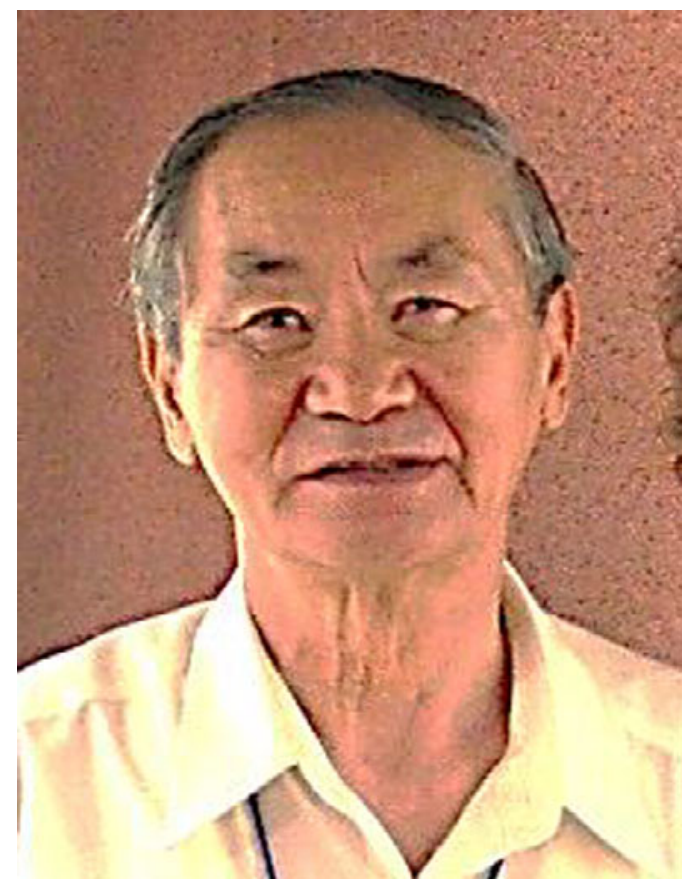

Figure 3. Founding Chairperson of the C41 Astronomical Instruments Working Group, Nha Il-Seong, at the archives-historical instruments conference he organised in South Korea in 2002 (photograph: Wayne Orchiston).

Subsequently, a Resolution about the "...identification, documentation, and preservation of surviving instruments and sites connected with the measurement of the arc of the meridian made by F.G.W Struve." (Orchiston et al. 2004d) was adopted at the C41 Business Meeting at the 1994 General Assembly in The Hague. For an overview of this important project, which was co-ordinated by the International Institution for the History of Surveying \& Measurement, see Batten \& Smith (2006); Smith (2005).

Eventually, a stand-alone Historical Instruments WG was set up at the 2000 General Assembly in Manchester, under the leadership of Professor Nha Il-Seong from South Korea (Fig. 3). The charter of the new WG was:

(a) to draw up an inventory of internationally-significant astronomical instruments;

(b) to assemble a bibliography of publications relating to such instruments; and

(c) to encourage colleagues to carry out research on historically-significant instruments and publish their results.

The WG also was responsible for tracking progress on the 1994 resolution about the Struve arc.

As we saw in Section 2.1 above, the founding Chairperson of the Historical Instruments WG, Professor Nha Il-Seong (together with Richard Stephenson and Wayne Orchiston) organized a conference on Astronomical Instruments and Archives from the Asia-Pacific Region, which was held in Cheongju, Korea, in 2002 July. The conference proceedings (Orchiston et al. 2004a) include nine papers on ancient astronomical instruments from China, India, Indonesia and Korea, an astrolabe in the National History Museum in Mexico City, and twentieth century optical and radio telescopes from Canada and Australia, respectively. These are listed in Nha (2006).

The following year the WG held a meeting at the 2003 GA in Sydney, where papers were presented on historical astronomical instruments in Australia, England, Italy, Japan, 
Russia, Scotland and the USA - for a listing of these see Nha (2006). Then in October 2004 the Fifth International Conference on Oriental Astronomy was held in Chiang Mai, Thailand, and papers about Chinese and South Korean astronomical instruments were included in the conference proceedings (Chen et al. 2006).

During the six year period 2000-2006 WG members were very active, publishing a number of books and chapters of books, and numerous papers in the Journal of the Antique Telescope Society, the Journal for the History of Astronomy, the Journal of Astronomical History and Heritage, and other journals. Apart from instruments already mentioned above, there also were papers about observatories, telescopes and other astronomical instruments in Algeria, France, Germany, Netherlands, New Zealand, Norway, Sweden and from Babylonia and the Mediterranean region. Papers and books also were published on Arabic and Islamic astronomical instruments. Some of these are listed in Orchiston et al. (2004d).

In addition, in 2005 C41's involvement on behalf of the IAU in the Struve arc of the meridian, initiated in 1994, finally ended. Gurshtein et al. (2006) report that "Under the watchful eye of Dr Alan Batten all the necessary procedures were successfully completed. The Struve arc has been officially recognized as an outstanding part of World Cultural Heritage."

The only unsuccessful project tackled by the WG during 2000-2006 was an attempt to develop an in-house system to inventory historically-significant astronomical instruments world-wide (Nha 2006). When it became apparent that science museums and the Scientific Instrument Commission of the International Union of History and Philosophy of Science had already developed a suitable internationally-standardized classificatory scheme, the WG abandoned its own attempt to develop such a scheme (see Schechner et al. 2011).

Given UNESCO's 2009 International Year of Astronomy, during the 2006-2009 triennium WG members began planning a major conference to be held in Venice to commemorate the 400th anniversary of Galileo's first observations with the telescope (Pigatto et al. 2008), and this also became the main initiative of the WG during the 2009-2012 triennium:

"The conference aims to highlight mankind's path towards an improved knowledge of the sky using mathematical and mechanical tools as well as monuments and buildings, giving rise, in so doing, to scientific astronomy. It will analyze similarities and differences among cultures and countries in exploiting the shared resource that the sky represents, and will examine the historical-political and scientific background favoring the progress of scientific astronomy in different epochs and countries, progress that led to a crucial turning-point for observational astronomy when Galileo turned the telescope to the night sky and initiated the New Astronomy." (Schechner et al. 2011).

Astronomy and Its Instruments Before and After Galileo was a highly-successful joint conference of the IAU and the INAF-Astronomical Observatory of Padova. It ran from 27 September to 3 October 2009, and attracted a large international audience. Subsequently, the proceedings were published by Pigatto \& Zanini (2010).

One year before the Venice meeting, Wayne Orchiston and colleagues organised the Sixth International Conference on Oriental Astronomy, which was held in Townsville, northern Australia, in July 2008. Among the papers presented was one about a Korean planisphere (see Orchiston et al. 2011).

One year after the Venice meeting, several prominent members of C41 organised the Seventh International Conference on Oriental Astronomy (ICOA-7), which was held in Tokyo, Japan, in October 2010. Papers were presented on Indian astrolabes, Japanese 
planispheres, South Korean time-keeping instruments and twentieth century astronomical instruments found in Japan and Uzbekistan, and published in the proceedings (see Nakamura et al. 2011).

Schechner et al. (2011) point out that since its foundation,

"... the concerns of the Working Group have expanded to include efforts to preserve and protect old astronomical instruments, observatories, and related sites as world cultural heritage and material evidence of the development of astronomy in different parts of the globe."

This was inspired by the founding of the C41 Astronomy and World Heritage WG in 2008, and a close bond developed between the two WGs which shared many members in common.

The Historical Instruments WG was wound up in 2014, and it was not reactivated after the Hawaiian GA. During its 15-year existence this IAU WG achieved a great deal, and maintained close links with the Scientific Instrument Commission of the International Union for the History and Philosophy of Science/Division of History of Science and Technology and the Working Group for the Preservation of Astronomical Heritage of the American Astronomical Society (Schechner et al. 2011). Collectively, these groups made a major contribution to our increased understanding of historically-significant astronomical instruments, and the importance of the major international conferences organised by key WG members in 2002 and 2009 cannot be under-estimated.

\subsection{Transits of Venus}

At the 2000 Manchester GA the following Type C (Commission) resolution was approved at the $\mathrm{C} 41$ Business Meeting:

"Recognizing the historical importance of previous transits of Venus and the numerous transit of Venus expeditions mounted by many countries, and noting the rarity of the upcoming transits of 2004 and 2012, Commission 41 recommends that the sites of the previous transit of Venus expeditions be inventoried, marked and preserved, as well as instrumentation and documents associated with these expeditions" (Dick \& Orchiston 2000).

This resolution led directly to the formation of a C41 Transits of Venus WG, under the leadership of Australia's Dr Wayne Orchiston (Fig. 4), and

"In addition to inventorying, marking, and preserving the sites of previous transit of Venus expeditions and researching the instruments used at these sites and the observations made, the WG also aims to prepare a bibliography of existing publications relating to all transits of Venus, and encourage colleagues to carry out further research and to publish their results" (Orchiston et al. 2002).

With the upcoming 2004 transit serving as an incentive, during the 2000-2003 triennium the WG was very active:

"ICHA members in Australia, Brazil, Canada, Italy, Japan, South Africa, UK, and the USA actively researched various transits and other means of establishing the solar parallax, resulting in a number of different publications (e.g. see Hughes, 2001; Orchiston, Love \& Dick, 2000; Pigatto \& Zanini, 2001; Schaefer, 2001), and the WG Committee prepared a bibliography of post 1989 research papers on transits of Venus. In light of the up-coming 2004 and 2012 transits, a number of popular books were published" (Stephenson et al. 2003). 


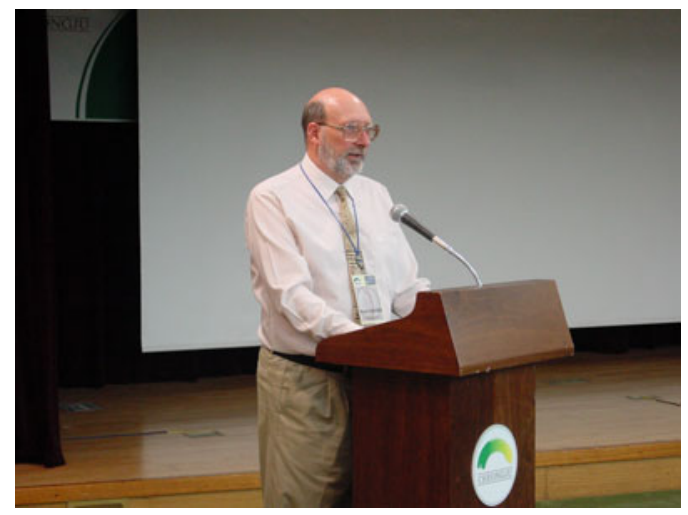

Figure 4. Founding Chairperson of the C41 Transits of Venus Working Group, Wayne Orchiston, attending a conference in South Korea in 2002 (photograph: Wayne Orchiston).

In addition to the nations mentioned above, there were active WG members in England, Germany, the Netherlands and Scotland. Meanwhile, books published were The Transit of Venus: The Brief Brilliant Life of Jeremiah Horrocks, Father of British Astronomy (Aughton 2004), Hōkūloa: The British 1874 Transit of Venus Expedition to Hawaii (Chauvin 2003), Transit of Venus: The Scientific Event that Led Captain Cook to Australia (Lomb 2004), Jeremiah Horrocks: Younger Genius 8 First Venus Transit Observer (Marston 2004), Transit: When Planets Cross the Sun (Maunder \& Moore 2000), Transit of Venus: 1639-2012 (Mourão 2004), The Transit of Venus: The Quest to Find the True Distance of the Sun (Sellars 2001), Transits of Venus (Sheehan \& Westfall 2004), and Vénus Devant le Soleil. Comprendre et Observer un Phénomène Astronomique (Simaan et al. 2003), while “... Steven Dick's [2002] monumental history of the U.S. Naval Observatory contains a sizable chapter about the 1874 and 1882 transit programmes" (Orchiston et al. 2002).

Apart from writing books and research papers, members of the WG also reported on existing historical markers erected to commemorate earlier transits, and arranged for a number of new markers to be installed (see Dick 2006; Orchiston et al. 2005b). Other members of the WG were active in arranging exhibitions and displays at museums, science centres, planetariums and observatories, and several excellent web-sites about the historic transits of Venus were set up (cf. Orchiston et al. 2002; Duerbeck et al. 2011).

After discussing the inaugural 'Progress Report' of the WG, the third 'Progress Report' begins with the following summary: "With the up-coming June transit, it is no surprise that there has been a worldwide flurry of recent interest in transits of Venus." (Orchiston et al. 2004d). The Report then goes on to discuss various historical reenactments arranged for June 2004 in Australia, Canada, South Africa, Switzerland and the USA, and provides a list of all known historical transit of Venus plaques and monuments. Mention also is made of new plaques intended for sites in Canada and South Africa. Further information also is supplied about new transit of Venus exhibitions in Australia, South Africa and the USA. This whole theme is developed further in the next published annual report of the WG (see Orchiston et al. 2005b).

In 2003 and 2004 there was "... a plethora of transit of Venus special lectures, seminars, workshops and conferences" (Orchiston et al. 2004d). The first major opportunity for WG members to discuss their research was during a half-day WG meeting at the 2003 IAU GA in Sydney. Subsequently, papers from that meeting, about Australian, Belgian, German, Italian, New Zealand and USA transit observations were published in a dedicated 2004 issue of the Journal of Astronomical History and Heritage and the special 
archives-transits of Venus issue of the Journal of Astronomical Data mentioned above in Section 2.1 (Sterken \& Duerbeck 2005).

The following year, the IAU organised a special highlight, an international conference (Colloquium 196), Transits of Venus: New Views of the Solar System and Galaxy, in association with the 8 June 2004 transit of Venus. The WG Chair by this time was America's Dr Steven Dick, and he reported:

"The meeting was held at the University of Central Lancashire, Preston, UK, near the site where Jeremiah Horrocks first observed a transit of Venus in 1639. To the delight of all present, on the day of the rare event almost the entire transit was observed from the tiny Lancashire village of Much Hoole, where Horrocks lived, and several other locations. Members of Commission 41 who presented historical papers included Allan Chapman, Suzanne Débarbat, Wayne Orchiston, Luisa Pigatto, Steven Dick, Brian Warner and Mary T. Brück. There was also an excellent set of scientific papers" (Dick 2006).

Orchiston et al. (2004d) elaborate:

"C4/ICHA is well-represented, with Suzanne Débarbat (France), Steven Dick (USA), Julieta Fierro (Mexico), Wayne Orchiston (Australia), Jay Pasachoff (USA), and Luisa Pigatto (Italy) on the Scientific Organising Committee; Peter Hingley (UK) on the Local Organising Committee; Allan Chapman (UK) as a Keynote Speaker; and Steven Dick, Wayne Orchiston and Richard Strom (Netherlands) as Invited Speakers."

Subsequently Professor Don Kurtz (Kurtz 2005) published the proceedings, which included a variety of papers about the 1639, 1761, 1769, 1874 and 1882 transits. In their 2003-2006 report for Commission C41, Gurshtein et al. (2006) announced that "This Colloquium and Proceedings are undoubtedly among the highlights of the history of astronomy within the triennium in question."

As an indication of the level of research that the 2004 transit inspired, the WG's fourth Progress Report (Orchiston et al. 2005b) contained a list of 45 publications, many of which were published during the one-year interval after the previous WG report was produced. These publications report on the 1639, 1761, 1769, 1874 and 1882 transits; expeditions mounted by Australia, Austria, Belgium, Brazil, England, France, Germany, Hungary, Italy, the Netherlands, New Zealand and the USA; instruments used on some of the transit expeditions; and transit of Venus archives.

After the flurry of activity generated by interest in the 2004 transit, there was low-level interest in the historical transits of Venus during the IAU 2006-2009 triennium. The Triennial Report of the WG for this period (Duerbeck et al. 2011) lists 17 new research papers, but about half of these were chapters in the following book: L'Événement Astronomique du Siècle? Histoire Sociale des Passages de Vénus 18741882 (Aubin 2006). Furthermore, Jessica Ratcliff was undoubtedly inspired by the 2004 transit (and perhaps the up-coming 2012 transit) to complete a D.Phil. at Oxford University on British involvement in the 1874 transit, and subsequently her thesis also was published as a book (Ratcliff 2008).

The Triennial Report of the WG for 2009-2011 mentions the continued low level of interest in the historical transits of Venus (Duerbeck et al. 2011), but the report does list six new papers and a new book, Transit of Venus: 1631 to the Present (Lomb 2011), along with several papers that report on the 2004 transit. Two of the six papers were co-authored by the American microbiologist Stella Cottam, who in 2011 completed a part-time off-campus Ph.D. through James Cook University (Australia) about nineteenth century transits of Venus and solar eclipses. After the 2012 transit, she and one of her 
supervisors, Associate Professor Wayne Orchiston, developed her thesis further into a book (Cottam \& Orchiston 2015).

The 2012 transit also prompted a conference that was held in Troms $\varnothing$, Norway, on 2-3 June 2012, and was mainly about the 1761 and 1769 transits. The proceedings of this conference (Sterken \& Aspaas 2013) include a number of papers by members of the IAU WG.

Finally, the plan always was to terminate the Transits of Venus WG after the 2012 transit and this is precisely what happened, but only after the unexpected death of its then-Chair, Dr Hilmar Duerbeck (see Dick \& Sterken 2018) on 5 January 2012. As founder of the WG, Professor Wayne Orchiston then resumed the Chair until the WG was closed down. The Transits of Venus Working Group had very successfully served its intended function: it held WG Meetings at most IAU GAs and a separate international conference in 2004; it encouraged wide-ranging research on the 1761, 1769, 1874 and 1882 transits, and facilitated the publication of about a dozen books and a large number of research papers; it spawned new web-sites; and it forged international research collaborations. It was one of the notable success stories of IAU Commission C41.

\subsection{Historic Radio Astronomy}

This new Working Group was established at the July 2003 IAU General Assembly in Sydney, as a result of the following resolution:

\section{"Recalling}

that the birth of radio astronomy brought an exciting new added multiwavelength dimension to astronomical research;

recognizing

that this new investigative technique led to a major change in our perspective of the cosmos; and

noting

that many of surviving pioneers of radio astronomy from the era 1940-1960 are now elderly, and much of the instrumentation that was used for radio astronomical investigations during these formative years is now lost to us, recommends

that every effort be made to identify, document and preserve surviving examples of historically-significant radio telescopes and ancillary instrumentation and to document the research programs carried out with this equipment, and requests

that in order to pursue this important radio astronomical heritage project IAU Commission 41 and the Inter-Union Commission for History of Astronomy collectively form an Historic Radio Astronomy Working Group with a Committee comprising W. Orchiston (Australia - Chair), K. Kellermann (USA), M. Goss (USA, B. Slee (Australia) and W. Sullivan (USA)."

The role of the new WG (Orchiston et al. 2004f) was to:

(a) assemble a master list of surviving historically-significant radio telescopes and associated instrumentation found world-wide;

(b) document the technical specifications and scientific achievements of such instruments;

(c) maintain an on-going bibliography of publications on the history of radio astronomy;

(d) monitor other developments relating to the history of radio astronomy.

This was a joint initiative of Commissions 40 (Radio Astronomy) and 41 (History of Astronomy), and as such the new WG came under the umbrella of both Commissions and Divisions X and XII. The founding Chairperson was Dr Wayne Orchiston from Australia 


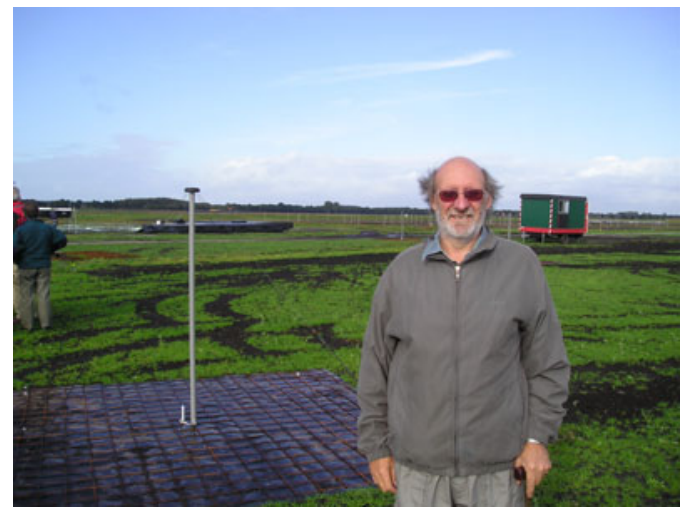

Figure 5. Founding Chairperson of the IAU C40-C41 Historic Radio Astronomy Working Group, Wayne Orchiston, visiting a windswept Netherlands LOFAR site in October 2009 (photograph: Richard Strom).

(see Fig. 5), and one of the objectives of the WG was to access information from surviving pioneers of radio astronomy while this was still possible (and it is a sad reflection today, in 2018, that during the intervening 15 years since the WG was formed almost all of these people have died).

Coincident with the founding of the WG, IAU Commissions 40 (Radio Astronomy) and 41 (History of Astronomy) organised one and a half days of meetings on the history of radio astronomy at the Sydney General Assembly, and these attracted large audiences. The one-day meeting on early Australian radio astronomy, featured Bob Bachelor, John Brooks, Bob Duncan, Eric Finlay, Bevan Jones, Bruce McAdam, Don McLean, Doug Milne, Harry Minnett, John Murray, Brian Robinson, Mal Sinclair, Bruce Slee, Woody Sullivan, Shigemasa Suzuki and John Whiteoak (one-third of whom have since died). Meanwhile, the half-day meeting on Pioneering observations in radio astronomy attracted papers about Elizabeth Alexander; Ruby Payne-Scott; Grote Reber; Olof Rydbeck; the international role of Würzburg dishes in early radio astronomy; early French, Japanese and Russian radio astronomy; the discoveries of Sgr A and A*; interstellar scintillations; and interpretation of the Dover Heights radio astronomy site. Titles of all of these Sydney GA papers are listed in Orchiston et al. (2004f).

In July 2002 the afore-mentioned conference on Astronomical Instruments and Archives from the Asia-Pacific Region (see Orchiston et al. 2002) was held in South Korea, and two of the papers published in the proceedings were about Australian radio astronomy.

From 27 to 30 August 2003 some members of the WG were involved in the JENAM2003 symposium on Radio Astronomy at 70: From Karl Jansky to Microjansky, which was held in Budapest, Hungary. Although the bulk of the papers were on contemporary radio astronomy, the first session of the conference was devoted to historical issues and included papers by Bernard Burke, Francis Graham-Smith and Alistair Gunn. Their papers, and others presented at the Conference, were published in the proceedings (Gurvits et al. 2005), and are listed in Orchiston et al. (2005a).

In June 2004 a conference was held at the University of Washington, Seattle, to celebrate Professor Woody Sullivan's 60th birthday, and the resulting book (Orchiston 2005) contained papers on historical radio or radar astronomy by Bruce Balick, Marshall Cohen, Alastair Gunn, Richard Jarrell, Ken Kellermann, Wayne Orchiston \& Bruce Slee, and Richard Strom. Details of these papers are provided in Orchiston et al. (2005a). 
In October 2004 at the Fifth International Conference on Oriental Astronomy (ICOA-5) held in Chiang Mai, Thailand, Richard Strom and Richard Stephenson organized a special session on Supernovae: Historical Records and Observations. Subsequently, the papers presented by John Dickel and by Wayne Orchiston \& Bruce Slee were published in the conference proceedings (see Chen et al. 2006).

The Second Progress Report of the WG also described history of radio astronomy research projects being carried out by 14 different members of the WG, discussed the development of the NRAO Archives and reported on The Preservation and Destruction of Historically-Significant Radio Telescopes (see Orchiston et al. 2005a). By 2006 the number of WG members conducting research on early radio astronomy had risen to 26 (see Orchiston et al. 2006).

To cater to the growing demand, all 2005 and 2006 issues of the Journal of Astronomical History and Heritage were dedicated to Australia's Dr Bruce Slee and contained sections on the history of radio astronomy. Published papers dealt with developments in Australian, Dutch, Indian, Swedish and USA radio astronomy.

The 2006 Prague IAU GA included a one-day WG Science Meeting devoted to The History of European Radio Astronomy and a half-day Science Meeting on Radio Astronomy Fifty Years Ago: From Field stations to Big Science' (Orchiston et al. 2008). Papers from the first meeting were published in a special dedicated issue of Astronomische Nachrichten (Wielebinski et al. 2007), and are listed in Kellermann et al. (2009) along with papers presented at the Field stations to Big Science Meeting. By the time of the Prague GA the membership of the WG had grown to ". . . about one hundred astronomers who are active in the history of radio astronomy field or interested in it. More than 30 WG members actively researched aspects of radio astronomical history during 2005-2007" (Orchiston et al. 2008). This is a quantum jump from the half-dozen who were researchactive in this field when the WG was founded just three years earlier. Some WG members

"... actively worked on national masterlists [of surviving historically-significant radio telescopes] for Australia, Germany, the Netherlands, the United Kingdom and the USA, and a number of research papers were prepared documenting individual instruments or instruments and research associated with specific radio astronomy field stations" (Orchiston et al. 2006).

In another major development, in 2005 James Cook University in Townsville (Australia) began offering Ph.D. and Master of Astronomy degrees in the history of radio astronomy for part-time off-campus students, supervised by Wayne Orchiston, Alastair Gunn, Bruce Slee, Richard Strom and Richard Wielebinski. The first graduates were Peter Quinn (M.Astr.), Harry Wendt (Ph.D.) and Ron Stewart (Ph.D.), followed later by Peter Robertson (Ph.D.) and Martin George (Ph.D.). Edward Walusku also completed the first draft of his Ph.D. thesis in 2008, but sadly he died after a long battle with cancer before he could revise his thesis and formally submit it. He did, however, manage to publish one research paper based on his research (Waluska 2007). Thesis topics of the above-mentioned students are listed in Kellermann et al. (2009).

At the Sixth International Conference on Oriental Astronomy (ICOA-6) held at James Cook University (JCU), Townsville, in July 2008 there was special emphasis on the history of Australian radio astronomy, which accounted for about one half of the 676-page proceedings (Orchiston et al. 2011). These papers were authored or co-authored by Ron Stewart and Harry Wendt, and their Ph.D. supervisors, Wayne Orchiston and Bruce Slee, and reviewed the Dapto, Murraybank and Potts Hill field stations, research conducted by the late Professor W.N. (Chris) Christiansen and Dr J. Paul Wild, and early Australian solar radio astronomy. Individual papers in this volume are listed in Kellermann et al. (2009). 
By the time the 2006-2009 Triennial Report was published (Kellermann et al. 2009), 52 different WG members were listed who were actively researching the history of radio astronomy, in Australia, China, England, France, Germany, India, the Netherlands, Russia, Ukraine and the USA. Books published during this period included Two Paths to Heaven's Gate (Conklin 2006), Under the Radar - The First Woman in Radio Astronomy: Ruby Payne-Scott (Goss \& McGee 2009), From Clark Lake to the Long Wavelength Array: Bill Erickson's Radio Science (Kassim et al. 2005), But It Was Fun: The First Forty Years of Radio Astronomy at Green Bank (Lockman et al. 2007), The Early Years of Radio Astronomy: Reflections Fifty Years After Jansky's Discovery (Paperback Edition Sullivan 2005) and most significantly, Cosmic Noise: A History of Early Radio Astronomy (Sullivan 2009).

The WG held two Science Meetings during the 2009 IAU GA in Rio de Janeiro, a half-day on The Development of Aperture Synthesis Imaging in Radio Astronomy and a quarter-day on Recent Research. Papers presented or displayed at these meetings discussed Australia, British and USA radio astronomy and are listed in Kellermann et al. (2009).

WG members were involved in the 50th anniversary celebrations of the National Radio Astronomy Observatory (USA) in 2008 and Parkes Radio Telescope (Australia) in 2011, and the 40th anniversary of Westerbork (2010) and Effelsberg (2011), all of which included historical papers. In 2009 Kellermann and Ekers organised a session on Discoveries in Astronomy at the American Philosophical Society, with emphasis on radio astronomy. Others who gave papers were Maarten Schmidt, Malcolm Longair and Robert Wilson (for details see Kellermann et al. 2011). In 2011 L.G. Kenwolf completed an M.A. thesis through the History Department at West Virginia University about "...personal issues associated with the establishment and operation of the NRAO in Green Bank" (Kellermann 2012b).

Books published during the 2012-2015 Triennium included Frontiers of Astrophysics: A Celebration of NRAO's 50th Anniversary (Bridle et al. 2008), Making Waves: The Story of Ruby Payne-Scott, Australian Pioneer Radio Astronomer (Goss 2012) and A Brief History of Radio Astronomy in the USSR (translated by Kellermann 2012a).

Since its foundation, the WG has been involved in two large-scale national research projects: to research and write up the early history of radio astronomy in France and in Japan. The former project ran from 2006 to 2011, and was co-ordinated by James Lequeux, Wayne Orchiston and Jean-Louis Steinberg, with assistance from Jacques Arsac, Émile-Jacques Blum, André Boischot, Suzanne Débarbat, Jean Delannoy, Pierre Encrenaz, Jesús Gómez-González, Mukul Kundu and Monique Pick. It resulted in the publication of seven research papers in the Journal of Astronomical History and Heritage $(J A H H)$.

The IAU Early Japanese Radio Astronomy Project began in 2012 and is on-going. It is co-ordinated by Masato Ishiguro and Wayne Orchiston, and to date five research papers have been published (all in $J A H H$ ).

The WG has had mixed results in its endeavours to preserve historically-significant radio telescopes or parts thereof. Attempts to prevent the destruction of Stanford University's solar array and five 60-ft dishes were unsuccessful, but the pillars at the solar array containing the chiselled signatures of many of the world's foremost radio astronomers were preserved and transferred to the NRAO site at Green Bank. Kellermann et al. (2011) report other successes:

"The Bell Labs horn reflector used by Penzias and Wilson to detect the CMB has been refurbished. In the Netherlands, the 25-meter Dwingeloo dish, inaugurated in 1956, and used for major research programs up to 1998, has been repaired and 
modernized by AMRAS, a foundation run by radio amateurs, since 2006. The Dutch Ministry of Education, Culture and Science has granted a major subsidy for the full restoration of the telescope, to be started in 2012."

By way of contrast, in 2005 WG members discovered that a local farmer had bulldozed all of the surviving antennas of the famous Chris Cross solar grating array near Sydney (see Orchiston \& Mathewson 2009) without consulting any members of the Australian radio astronomy community. This was a major heritage loss for Australian and world radio astronomy.

From 2003 the National Radio Astronomy Observatory at Charlottesville, Virginia has developed its Archives (see Kellermann et al. 2011), which by 2015 housed substantial records on early U.S. radio astronomy, including material accumulated by Woody Sullivan in researching his masterpiece, Cosmic Noise: A History of Early Radio Astronomy (Sullivan 2005). At about the same time, the CSIRO's Australia Telescope National Facility in Sydney began cataloguing and scanning its unique collection of photographs about Australian radio astronomers and radio astronomy (e.g. see Orchiston 2001; Orchiston et al. 2004b).

As is inevitable with a WG that focused (at least, initially) on the immediate post-WWII developments in astronomy, many of the pioneers of international radio astronomy died between the founding of our WG and the 2015 IAU GA. They included: Don Backer (USA), John Baldwin (England), Ron Bracewell (Australia and U.S.A.), Émile-Jacques Blum (France), Semion Braude (Ukraine), Geoffrey Burbidge (England), Tom Carr (USA), W.N. (Chris) Christiansen (Australia), Robin Conway (England), Jean-François Denisse (France), Bob Duncan (Australia), Bill Ellis (Australia), Shinzo Enome (Japan), Frank Gardner (Australia), Georgij Gelfreikh (Russia), Vitali Ginzburg (Russia), Bill Gordon (USA), Stan Gorgolewski (Poland), Fred Haddock (USA), Robert Hanbury Brown (U.K. and Australia), David Heeschen (USA), Victor Hughes (U.K. and Canada), Yuri Ilyasov (Russia), Naum Kaidanovsky (Russia), Kinaki Kawabata (Japan), Vladimir Kotelnikov (Russia), John Krauss (U.S.A.), Mukul Kundu (India \& U.S.A.), Arcadij Kuzmin (Russia), Norman Labrum (Australia), Thomas Legg (Canada), Jack Locke (Canada), Fred Lo (USA), Sir Bernard Lovell (England), Bernie Mills (Australia), Harry Minnett (Australia), Masaki Morimoto (Japan), Koh-Ichiro Morita (Japan), Lex Muller (Netherlands), Vengataraman Radhakrishnan (India), Ernst Raimond (Netherlands), Grote Reber (U.S.A. and Australia), Jorma Riihimaa (Finland), Brian Robinson (Australia), Vagharshak Sanamian (Armenia), Kevin Sheridan (Australia), Slava Slysh (Russia), Gordon Stanley (Australia and U.S.A.), Jean-Louis Steinberg (France), Atsushi Tsuchiya (Japan), Henk van de Hulst (Netherlands), Kevin Westfold (Australia), J. Paul Wild (Australia), Gisbert Winnewisser (Germany) and Don Yabsley (Australia). Where possible, WG members endeavoured to publish obituaries or biographical review papers of these and other deceased radio astronomers (e.g. see Kellermann et al. 2011; Orchiston et al. 2004f, 2005a).

The Historic Radio Astronomy WG continued to develop further during the 2012-2015 Triennium, and was one of the resounding success stories of Commissions 40 and 41 when it was wound up in 2014. For some unexplained reason, after the Hawaiian GA it was re-established as a WG only of Commission B4 (Radio Astronomy).

\subsection{Astronomy and World Heritage}

This WG is undoubtedly the major success story of C41, and although it was motivated primarily by international astro-politics, it was the catalyst that encouraged a number of C41 members to carry out research on historic observatories and astronomical structures and on sites of astronomical significance. 


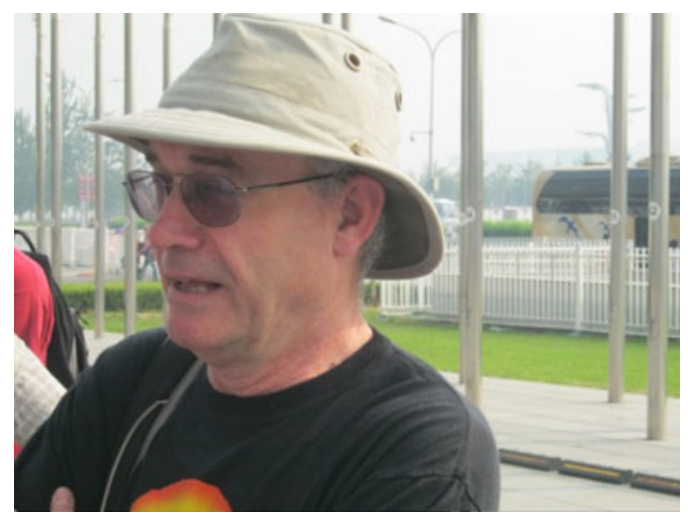

Figure 6. Founding Chairperson of C41's Astronomy and World Heritage Working Group, Clive Ruggles, during the Beijing IAU General Assembly in 2012 (photograph: Wayne Orchiston).

Gurshtein et al. (2006) explain that from 2003

"...the Commission as a group and several individual fellows of C41 have participated actively ... in the development of a new thematic initiative Astronomy and the World Heritage within UNESCO. The initiative was preliminarily approved by UNESCO's World Heritage Committee in July 2005, opening the way for relationship to astronomy [sic] to become one of the criteria under which UN member states may nominate cultural properties for inclusion in the World Heritage List."

The dynamic founder of C41's Astronomy and World Heritage WG was England's Professor Clive Ruggles (see Fig. 6), and as he and the then Vice-President, Professor Gudrun Wolfschmidt (Ruggles \& Wolfschmidt 2011) explain:

"The WG was created in 2008 to progress UNESCO's Astronomy and World Heritage Initiative (AWHI) jointly with the World Heritage Centre, following the signing of a formal Memorandum of Understanding between the IAU and UNESCO.

The AWHI is a thematic initiative aiming to identify, safeguard and promote cultural properties connected with astronomy... One of the main objectives of the $W G$ is to help to establish guidelines for State Parties to the World Heritage Convention who wish to nominate sites for inscription on the World Heritage List on the grounds of their relationship to astronomy."

The WG then established two flagship projects:

(a) to work with the International Council of Sites and Monuments and prepare a Thematic Study on the Heritage Sites of Astronomy (see Ruggles \& Cotte 2010; cf. Wolfschmidt 2009); and

(b) to develop an Astronomical Heritage Portal (as a follow-up to the Thematic Study). This has since become the main web-site for the UNESCO Astronomy and World Heritage Initiative (Ruggles \& Wolfschmidt 2011).

Following a meeting in September 2010 the WG began developing extended case studies for 11 selected sites.

In order to maintain the momentum already generated and continue the Astronomy and World Heritage Initiative, the WG applied successfully to reform as a stand-alone commission following the Hawaiian IAU GA. 


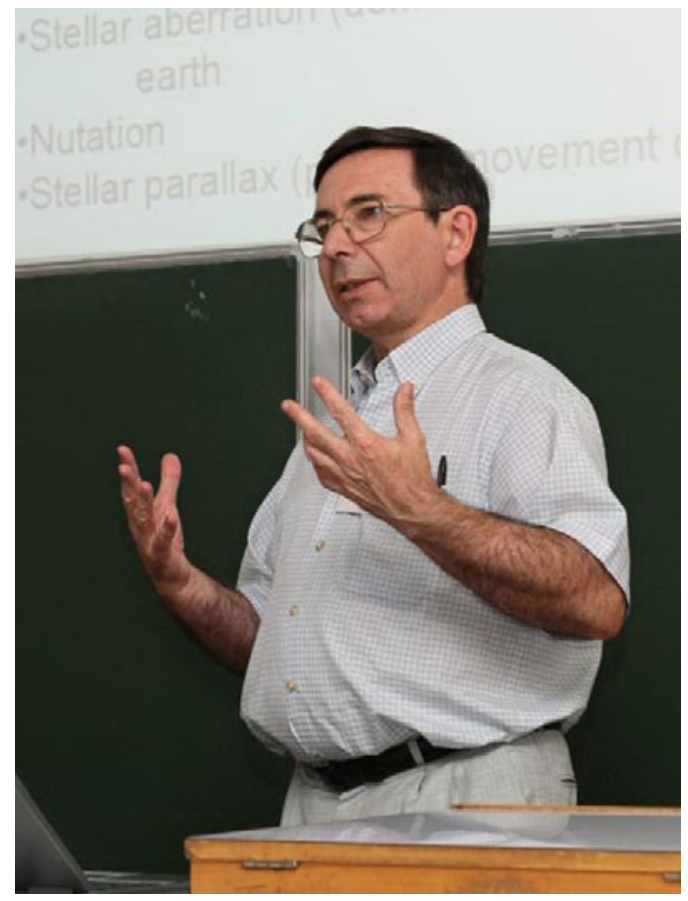

Figure 7. A recent photograph of the Founding Chairperson of C41's Johannes Kepler Working Group, Terry Mahoney (photograph courtesy: Terry Mahoney).

\subsection{Johannes Kepler}

This was the last of the C41 WGs to be formed, and was launched in 2009 at the Rio de Janeiro GA. The founding Chairperson was the Spain-based British astrophysicist, Terence J. Mahoney (Fig. 7), and the rationale of the WG was to promote studies of Johannes Kepler through:

(a) Representations at international level with other organizations and institutions, specifically the International Council for Science (ICSU) and its member organizations (e.g. the International Union of History and Philosophy of Science);

(b) Establishing an IAU Working Group web-site dedicated to Johannes Kepler and his works;

(c) Encouraging research and publication, including translations of Kepler's works into modern languages;

(d) Formulating and carrying out a programme of digitization of first and early editions of Kepler's works and associated material;

(e) Investigating the possibility of digitizing Kepler's collected works (Johannes Kepler: Gesammelte Werke, 1937-), now nearing completion under the editorship of the Kepler Commission of the Bavarian Academy of Sciences (the full digitized version of the Gesammelte Werke is now available free to the public); and

( $f$ ) Considering the feasibility of digitizing the manuscript material owned by the Russian Academy of Sciences.

In 2010, just one year after the WG was founded, members of the WG were responsible for the preparation of the following book: Kepler's Heritage in the Space Age: 400th Anniversary of Astronomia Nova (Hadravová et al. 2010). Meanwhile, WG members are now working on another book, Reading the Mind of God: Johannes Kepler and the Reform of Astronomy. This will contain chapters by the world's leading Kepler specialists 
(Kochhar et al. 2015), and will be published by Springer. One of the other challenges of the WG is to develop a comprehensive Johannes Kepler web-site.

Following the Hawaiian GA, the Johannes Kepler WG was the only original C41 WG that was reactivated and hosted solely by C41's replacement, Commission C3 (History of Astronomy).

\section{Discussion and Concluding Remarks}

On the basis of the level of research activity (measured in terms of publications and conferences and meetings organised) maintained throughout their existence, three of the seven C41 WGs were highly successful: Astronomy and World Heritage, Historic Radio Astronomy, Transits of Venus. Meanwhile, the Archives and Historical Instruments WGs were partially successful, and although it is serving a good purpose by investigating the achievements of a prominent European astronomer, at this stage it is premature to evaluate the Johannes Kepler WG. The Astronomical Chronology WG was the only C41 WG that did not achieve any of its primary objectives, and it is clear now that there was never a need for such a WG.

A quick examination reveals that each highly successful WG was successful for totally different basic reasons.

The Astronomy and World Heritage WG was inspired by a major UNESCO initiative, and formalized once the IAU and UNESCO had signed a Memorandum of Understanding. The IAU then committed to furthering the UNESCO initiative, and could most effectively achieve this by researching historic observatories, sites and instruments. This also offered a special opportunity for WG members to network effectively with existing members of the Historical Instruments WG.

The Historic Radio Astronomy WG was successful because it focused on what I term 'sexy science', radio astronomy (like astrobiology) being one of the glamour fields of astronomy and astrophysics. But the foundation of the WG also was timely, for it sought to exploit a unique opportunity: to tap into the memories, letters, photographs and archives of some of the international pioneers of radio astronomy while they were still with us (and this was possible by having key radio astronomers from different nations on the OC of the WG). So the Historic Radio Astronomy WG was set up at the right place (it had an international charter) and at the right time.

The Transits of Venus WG also was set up at the right place and the right time. Given the up-coming 2004 and 2012 transits, there was bound to be interest, also, in the historical transits, and between them these had involved astronomers from many different nations. So the international focus of the WG was assured. Moreover, the two twenty-first century transits offered special educational and outreach opportunities, as we have seen. But, unlike the Astronomy and World Heritage and the Historic Radio Astronomy WGs, which have on-going research potential, from the start the Transits of Venus WG was seen to have a finite life. Like a supernova, it exploded into international prominence in year 2000, achieved maximal visibility around the time of the 2004 transit, and then during its decline phase, experiencing a short-lived increase in visibility in 2012 before falling below the research threshold of all but the most dedicated researchers and disappearing from general view. It had served its purpose admirably!

When we look at the histories of the three most successful WGs, we immediately see that there were two other key factors that contributed to their success:

(a) All were led by committed and well-respected Chairpersons, who were supported throughout by strong OCs; and

(b) Each WG quickly attracted members and was able to achieve a critical mass that not only ensured its continuation but allowed for wide-range research activities. 
The Archives and Historical Instruments WGs also were founded and subsequently were led by highly-regarded astronomers, and although the Archives WG had wide IAU support - as witnessed by the resolutions passed prior to its formation - neither it nor the Historical Instruments WG was able to achieve the critical mass of members that made it sustainable. This was especially so of the Archives WG once it decided to focus on IAU archives from founding member countries, where such a project demanded the active co-operation of archivists and others who were not IAU members and had no vested interest in furthering the objectives of the WG. Meanwhile, the Historical Instruments WG seemed to lose momentum following its highly-successful conference in Venice in 2009, but maybe this was also because some of its key members were captivated by the Astronomy and World Heritage objectives and transferred their allegiance to this newly-formed C41 WG.

I would maintain that the early policy of publishing annual reports of the Archives, Historical Instruments, Transits of Venus and Historic Radio Astronomy WGs was important, not only for tracking the progress of the WGs after their formation, but for publicizing their achievements and attracting new members. Unlike the official IAU reports, which only appeared every three years and (initially) were relatively difficult to access, the C41 WG annual reports were published in the Journal of Astronomical History and Heritage, which quickly evolved into an e-journal that could be accessed free-of-charge from the ADS and National Astronomical Research Institute of Thailand web-sites.

The Archives, Historical Instruments, Transits of Venus, Historic Radio Astronomy and Astronomy and World Heritage WGs also made a point of scheduling dedicated sessions (generally Business Meetings and Science Meetings) at the different IAU GAs, which allowed for the evolution of the WG OCs and for members to discuss their recent research. But more than this, by offering a variety of different history of astronomy sessions at successive GAs, C41 members could justify the time and expense associated with attending a GA, where they were virtually guaranteed the opportunity to present oral or poster papers on their research. Because of competition from the various astrophysics commissions, over the years C41 found it extremely difficult to bid successfully for Joint Discussions or Special Session at GAs, but by having our own programmes and focusing on the WGs, attending the GAs became cost-effective nonetheless. I believe that these GA meetings were critical for the survival and development of C41 and its WGs, and I regret the current policy of minimizing WG sessions at IAU GAs.

But even the scheduling of WG Science Meetings at IAU GAs was not enough for active WGs, so - as we have seen - members set out to organise their own dedicated conferences, or to plan the inclusion of sessions relating to specific C41 WGs at conferences with wider coverage. This not only allowed for the continued discussion of C41 WG research, but the conference proceedings provided further publication outlets for a burgeoning astronomical community when the Journal for the History of Astronomy and the Journal of Astronomical History and Heritage were often over-subscribed. Having access to further publication options was critical, but at the same time the key role that these two journals played in fostering research by $\mathrm{C} 41 \mathrm{WG}$ members cannot be over-estimated.

I have suggested that one of the important contributory factors that led to the success of the individual C41 WGs was the status of their Chairpersons, and it is illuminating that almost all founding Chairpersons of the C41 WGs also at one time or another served as the President of the Commission, or its successor, C.C3 (see Table 2). The only notable exception is the Johannes Kepler WG Chair, Terry Mahoney, who, if history is any indication, will successfully stand for the Vice-Presidency of C.C3 at the 2021 election! 
Table 2. Presidents of IAU Commission C41, 1948-2015 and Commission C3, 2015-2021, and associated C41 Working Groups since 1991 (adapted from Kochhar et al. 2015)

\begin{tabular}{|c|c|c|c|}
\hline Years & President & Country & WG Involvement \\
\hline 1948-1952 & Otto Neugebauer & USA & \\
\hline $1952-1955$ & Herbert Dingle & $\mathrm{UK}$ & \\
\hline 1955-1958 & Herbert Dingle & UK & \\
\hline 1958-1961 & Piotr Grigorevich Kulikovsky & USSR & \\
\hline 1961-1964 & Piotr Grigorevich Kulikovsky & USSR & \\
\hline 1964-1967 & Eugeniusz Rybka & Poland & \\
\hline 1967-1970 & Eugeniusz Rybka & Poland & \\
\hline 1970-1973 & Owen Gingerich & USA & \\
\hline 1973-1976 & Owen Gingerich & USA & \\
\hline 1976-1979 & Jerzy Dobrzycki & Poland & \\
\hline 1979-1982 & Michael Hoskin & UK & \\
\hline 1982-1985 & Olaf Pedersen & Denmark & \\
\hline $1985-1988$ & John A. Eddy & USA & \\
\hline 1988-1991 & John North & UK & \\
\hline 1991-1994 & Suzanne Débarbat & France & $\begin{array}{l}\text { Archives (Founding Chair \& OC); } \\
\text { Historic Radio Astronomy (OC) }\end{array}$ \\
\hline 1994-1997 & S.M. Razaullah Ansari & India & \\
\hline $1997-2000$ & Stephen J. Dick & USA & Transit of Venus (Chair \& OC) \\
\hline 2000-2003 & F. Richard Stephenson & UK & \\
\hline 2003-2006 & Alexander Gurshtein & Russia/USA & $\begin{array}{l}\text { Astronomical Chronology (Founding Chair); } \\
\text { Transit of Venus (OC) }\end{array}$ \\
\hline 2006-2009 & Nha Il-Seong & South Korea & Historical Instruments (Founding Chair \& OC) \\
\hline 2009-2012 & Clive Ruggles & UK & Astronomy \& World Heritage (Founding Chair) \\
\hline $2012-2015$ & Rajesh Kochhar & India & $\begin{array}{l}\text { Astronomical Chronology (OC); Historical } \\
\text { Instruments (OC); Transit of Venus (OC) }\end{array}$ \\
\hline $2015-2018$ & Xiaochun Sun & China & \\
\hline 2018-2021 & Wayne Orchiston & Thailand & $\begin{array}{l}\text { Archives (OC); Historic Radio Astronomy } \\
\text { (Founding Chair \& OC); Historical Instruments } \\
\text { (OC); Transit of Venus (Founding Chair \& OC) }\end{array}$ \\
\hline
\end{tabular}

With the current IAU emphasis on Divisions, and a stated desire to limit the number of WGs (at least in Division C), we need to look closely at the rationale for establishing or maintaining WGs by Commission C3. We have clearly demonstrated that in the preHawaiian era (which I fondly refer to as 'the good old days') WGs were a very effective tool for fostering research and research collaborations in different specialist areas of the history of astronomy. I believe that they still have this potential, and that rather than limiting the number of WGs, the IAU should be encouraging the formation of new WGs - especially in the case of C.C3, given the very wide-ranging research of its members.

Not only is there a need to continue the Johannes Kepler WG and to re-establish the Historic Radio Astronomy WG as a joint venture of Commissions B4 (Radio Astronomy) and C3, but the existing C.C3/C4 WG on Cultural Astronomy (that was formed in 2015) needs to be split into two separate WGs, one for Archaeoastronomy and the other for Ethnoastronomy. These are very different research disciplines, and there is now a sufficient number of active researchers in each of these fields to justify the formation of two separate WGs. This can most effectively be achieved by rebadging the Cultural Astronomy WG so that its focus is Archaeoastronomy, and combining Ethnoastronomy with the existing WG on Intangible Heritage. The original C41 WG on Historical Instruments also should be re-established, but renamed Historical Instruments and Observatories and as a joint C.C3/C4 WG so that some of the research carried out by members can assist in furthering the IAU-UNESCO World Heritage Initiative.

Meanwhile, there are other specialist areas of the history of astronomy crying out for WGs. With more than one hundred astronomers actively researching aspects of Asian astronomy there are clear grounds for a new C.C3/C4 WG on Asian astronomy, and it is important that this networks effectively with existing groups, such as the OC of the 
International Conference on Oriental Astronomy (ICOA), the Silk Roads Astronomical Workshops, the National Astronomical Observatory of Japan History of Astronomy Conferences and the History \& Heritage WG of the Southeast Asian Astronomy Network (SEAAN).

Two other specialist areas of the history of astronomy that probably now have adequate numbers of researchers to justify the formation of WGs and certainly would benefit from co-ordination and the establishment of research collaborations are Applied Historical Astronomy and Arabic \& Islamic Astronomy.

Meanwhile, the need for a new C.C3/C4 WG on Astronomical Archives needs to be carefully assessed. Back in 2002 Suzanne Débarbat noted that:

"At the Korean Conference a number of our members highlighted the fact that archives underpin most historical research projects. This being the case, we hope that in the long run the activities of the Archives WG will prove to be of great benefit to the rank and file membership of C41 ..." (Débarbat 2002).

This is all very well, but if the focus of a new Astronomical Archives WG will again be on IAU archives, then funding support needs to be obtained from the IAU to make such a survey possible and to attract support from non-IAU participants. But before this can happen, perhaps a survey needs to be conducted on the current status of astronomical archive studies in different member nations of the IAU. One of the objectives of the original (C41) Archives WG was to establish and publish master lists of historicallysignificant archives for different countries. When I researched master lists for Australia and New Zealand, the greatest challenge I faced was to come up with a valid definition of 'historically-significant' in relation to astronomical archives (Orchiston 2004). This very same issue also emerges when one tries to assemble a master list of historically-significant astronomical instruments or decide which individual telescopes, for example, are worthy of study (e.g. see Orchiston 2010).

Kochhar et al. (2015) describe how

"Astronomy today is at the cutting edge of intellectual enquiry, and, at its most glamorous, a child of high technology. But it is more than a branch of modern science. It is a symbol of the collectivity and continuity of humankind's cultural heritage."

Current and future C.C3 WGs surely have an important role to play if they can help us unravel some of the finer details of humankind's cultural heritage.

\section{Acknowledgements}

I wish to thank the IAU and Springer for travel grants that made it possible for me to attend the Vienna GA. I also am grateful to Terry Mahoney for kindly supplying Fig. 7.

\section{References}

Aubin, D. (ed.) 2006, L'Événement Astronomique du Siècle? Historire Sociale des Passages de Vénus 1874-1882. Nantes, Université de Nantes

Aughton, P. 2004, The Transit of Venus: The Brief Brilliant Life of Jeremiah Horrocks, Father of British Astronomy. London, Weidenfeld \& Nicholson

Batten, A. H. \& Smith, J. R. 2006, J. Astron. Hist. ES Heritage, 9, 65

Blaauw, A. 1994, History of the IAU: The Birth and First Half Century of the International Astronomical Union. Dordrecht, Boston, and London, Kluwer

Bridle, A. H., Condon, J. J. \& Hunt, G. C. 2008, Frontiers of Astrophysics: A Celebration of NRAO's 50th Anniversary. San Francisco, Astronomical Society of the Pacific (Conference Series, Number 395) 
Chauvin, M. 2003, Hōkūloa: The British 1874 Transit of Venus Expedition to Hawaii. Honolulu, Bishop Museum Press

Chen, K.-Y., Orchiston, W., Soonthornthum, B. \& Strom, R. (eds.) 2006, Proceedings of the Fifth International Conference on Oriental Astronomy. Chiang Mai, University of Chiang Mai Press

Chinnici, I., Corbin, B. G., Débarbat, S. V., Green, D. W. E., Lee, J. -B., Matsuura, O. T., Orchiston, W., Perkins, A. \& Simonia, I. A. 2008, Division IX / Commission 41 / Working Group Archives. In van der Hucht, K. (ed.), Transactions of the IAU, Volume XXVIIA: Reports on Astronomy 2006-2009. Cambridge, Cambridge University Press. Pp. 420-422

Chinnici, I., Matsuura, O. T., Corbin, B., Débarbat, S., Green, D., Nakamura, T., Perkins, A. \& Simonia, I. 2011, Division IX / Commission 41 / Working Group Archives. In Corbett. I. (ed.), Transactions of the IAU, Volume XXVIIIA: Reports on Astronomy 2009-2012. Cambridge, Cambridge University Press. Pp. 398-399

Conklin, N. D. 2006, Two Paths to Heaven's Gate. Green Bank, National Radio Astronomy Observatory

Corbin, B. 2007, J. Astron. Hist. \& Heritage, 10, 72

Cottam, S. \& Orchiston, W. 2015, Eclipses, Transits, and Comets of the Nineteenth Century: How America's Perception of the Skies Changed. Cham (Switzerland), Springer

Débarbat, S. 2002, J. Astron. Hist. ES Heritage, 5, 181

Dick, S. J. 2002, Sky and Ocean Joined. The U.S. Naval Observatory, 1830-2000. Cambridge, Cambridge University Press

Dick, S. 2006, J. Astron. Hist. \& Heritage, 9, 205

Dick, S. \& Orchiston, W. 2000, J. Astron. Hist. \& Heritage, 3, 165

Dick, W. \& Sterken, C. (eds.), 2018, In Memoriam Hilmar Duerbeck. Leipzig, Leipziger Universitätsverlag

Duerbeck, H. W., Dick, S., van Gent, R., Hughes, D., Koorts, W., Orchiston, W. \& Pigatto, L. 2011, Division IX / Commission 41 / Working Group Transits of Venus. In Corbett. I. (ed.), Transactions of the IAU, Volume XXVIIIA: Reports on Astronomy 2009-2012. Cambridge, Cambridge University Press. Pp. 403-404

Goss, M. 2012, Making Waves: The Story of Ruby Payne-Scott, Australian Pioneer Radio Astronomer. Berlin, Springer

Goss, M. \& McGee, R. F. 2009, Under the Radar - The First Woman in Radio Astronomy: Ruby Payne-Scott. Springer

Gurshtein, A. A., Nha, I. -S., Ruggles, C., DeVorkin, D., Dick, W., Kochhar, R., Nakamura, T., Pigatto, L., Stephenson, R. \& Warner, B. 2006, Commission 41: History of Astronomy. In Engvold, O. (ed.), Proceedings IAU Symposium No. XXVIA: Reports on Astronomy 2002-2005. Cambridge, Cambridge University Press. Pp. 377-379

Gurvits, L. I., Frey, S. \& Rawlings, S. 2005, JENAM 2003. Radio Astronomy from Karl Jansky to Microjansky. PA deCourtaboeuf, EDP Sciences

Hadravová, A., Mahoney, T. J. \& Hadrava, P. 2010, Kepler's Heritage in the Space Age: 400th Anniversary of Astronomia nova. Prague, National Technical Museum

Hughes, D. W. 2001, J. Astron. Hist. E Heritage, 4, 15

Kassim, N. E., Perez, M. R., Junor, W. \& Henning, P. A. 2005, From Clark Lake to the Long Wavelength Array: Bill Erickson's Radio Science. San Francisco, Astronomical Society of the Pacific (ASP Conference Series, Volume 345)

Kellermann, K. I. (transl.) 2012, A Brief History of Radio Astronomy in the USSR. Dordrecht, Springer

Kellermann, K. I. 2012, J. Astron. Hist. \& Heritage, 15, 255

Kellermann, K., Orchiston, W., Davies, R., Lequeux, J., Kaifu, N., Ilyasov, Y., Swarup, G., Van Woerden, H., Wall, J. \& Wielebinski, R. 2009, J. Astron. Hist. \&6 Heritage, 12, 249

Kellermann, K.., Orchiston, W., Davies, R., Gurvits, L., Ishiguro, M., Lequeux, J., Swarup, G., Wall, J., Wielebinski, R. \& van Woerden, H. 2011, Division X, XII / Commission 40, 41 / Working Group [Historic] Radio Astronomy. In Corbett. I. (ed.), Transactions of the IAU, Volume XXVIIIA: Reports on Astronomy 2009-2012. Cambridge, Cambridge University Press. Pp. 311-313 
Kochhar, R., Sun, X., Ruggles, C., Belmonte Avilés, J. A., Corbin, B., Milone, E., Norris, R., Oigatto, L. [sic should be Pigatto] and Soma, M. [sic should be Sôma] 2015, History of astronomy under the auspices of the IAU. In Montmerle, T., (ed.), Transactions of the IAU, Volume XXIXA - Reports on Astronomy: Commission Legacy Reports. Cambridge, Cambridge University Press. Pp. 196-204

Kurtz, D. W. (ed.) 2005, Transits of Venus: New Views of the Solar System and Galaxy. Cambridge, Cambridge University Press

Lockman, F. J., Ghigo, F. D. \& Balser, D. S. 2007, But It Was Fun. The First Forty Years of Radio Astronomy at Green Bank. Green Bank, National Radio Astronomy Observatory

Lomb, N. 2004, Transit of Venus: The Scientific Event that Led Captain Cook to Australia. Sydney, Powerhouse Publishing

Lomb, N. 2011, Transit of Venus: 1631 to the Present. Sydney, New South Publishing

Marston, P. 2004, Jeremiah Horrocks: Younger Genius $\& 3$ First Venus Transit Observer. Preston, University of Central Lancashire

Maunder, M. \& Moore, P. 2000, Transit: When Planets Cross the Sun. London, Springer

Mourão, R. R. de F. 2004, Transit of Venus: 1639-2012. Brazil (in Portuguese)

Nakamura, T., Orchiston, W., Sôma, M. \& Strom, R. (eds.) 2011, Proceedings of the Seventh International Conference on Oriental Astronomy. Tokyo, National Astronomical Observatory of Japan

Nha, I.-S. 2006, J. Astron. Hist. \& Heritage, 9, 204

Nha, I.-S., Ruggles, C. L. N., Gurshtein, A. A., Kochhar, R. K., DeVorkin, D. H., de Jong, T., Nakamura, T., Orchiston, W., Vidiera, A. A. P. \& Warner, B. 2008, Commission 41 History of Astronomy. In van der Hucht, K. (ed.), Transactions of the IAU, Volume XXVIIA: Reports on Astronomy 2006-2009. Cambridge, Cambridge University Press. Pp. 415-419

Orchiston, W. 2001, ATNF News, 45, 12

Orchiston, W. 2004, J. Astron. Data, 10, 67

Orchiston, W. (ed.) 2005, The New Astronomy: Opening the Electromagnetic Window and Expanding our View of Planet Earth. A Meeting to Honor Woody Sullivan on his 60th Birthday. New York, Springer

Orchiston, W. 2010, J. Astron. Hist. \& Heritage, 13, 235

Orchiston, W. \& Mathewson, D. 2009, J. Astron. Hist. \& Heritage, 12, 11

Orchiston, W., Chapman, J. \& Norris, B. 2004b, The ATNF Historic Photographic Archive: documenting the history of Australian radio astronomy. In Orchiston et al. 2004a, 41-48

Orchiston, W., Love, T. \& Dick, S.J. 2000, J. Astron. Hist. \& Heritage, 3, 23

Orchiston, W., Dick, S., Gurshtein, A., Kochhar, R. \& Pigatto, L. 2002, J. Astron. Hist. \& Heritage, 5, 185

Orchiston, W., Dick, S. J., Duerbeck, H. W., van Gent, R., Hughes, D., Koorts, W. \& Pigatto, L. 2004c, J. Astron. Hist. \& Heritage, 7, 50

Orchiston, W., Dick, S. J., Duerbeck, H., van Gent, R., Hughes, D., Koorts, W. \& Pigatto, L. 2005b, J. Astron. Hist. \& Heritage, 8, 70

Orchiston, W., Nakamura, T. \& Strom, R. (eds.) 2011, Highlighting the History of Astronomy in the Asia-Pacific Region: Proceedings of the 6th International Conference on Oriental Astronomy. New York, Springer

Orchiston, W., Stephenson, F. R., Débarbat, S. \& Nha I. -S. 2004a, Astronomical Instruments and Archives from the Asia-Pacific Region. Seoul, IAU Commission 41

Orchiston, W., Nha, I.-S., Hamel, J., Johnson, K., Nakamura, T. \& Schechner, S. 2004d, J. Astron. Hist. $\mathcal{G}$ Heritage, 7, 57

Orchiston, W., Corbin, B., Chinnici, I., Débarbat, S., Dick, W., Green, D. \& Perkins, A. 2004e, J. Astron. Hist. \& Heritage, 7, 61

Orchiston, W., Davies, R., Denisse, J.-F., Kellermann, K., Morimoto, M., Slysh, S., Swarup, G. \& van Woerden, H. 2004f, J. Astron. Hist. \& Heritage, 7, 53

Orchiston, W., Bracewell, R., Davies, R., Denisse, J. -F., Goss, M., Gunn, A., Kellermann, K., McGee, D., Morimoto, M., Slee, B., Slysh, S., Strom, R., Sullivan, W., Swarup, G., Van Woerden, H., Wall, J. \& Wielebinski, R. 2005a, J. Astron. Hist. \& Heritage, 8, 65 
Orchiston, W., Davies, R, Kellermann, K., Lecacheux, A., Morimoto, M., Slysh, S., Swarup, G., Van Woerden, H., Wall, J. \& Wielebinski, R. 2006, J. Astron. Hist. \& Heritage, 9, 203

Orchiston, W., Kellermann, K. I., Davies, R. D., Débarbat, S. V., Morimoto, M., Slyh, S., Swarup, G., van Woerden, H., Wall, J. V., \& Wielebinski, R. 2008, Inter-Division IV-VIX / Working Group Historic Radio Astronomy. In van der Hucht, K. (ed.), Transactions of the IAU, Volume XXVIIA: Reports on Astronomy 2006-2009. Cambridge, Cambridge University Press. Pp. 344-345

Pigatto, L. \& Zanini, V. 2001, J. Astron. Hist. \& Heritage, 4, 43

Pigatto, L. \& Zanini, V. (eds.) 2010, Astronomy and its Instruments Before and After Galileo. Padua, Cooperativa Libraria Editrice Universit di Padova

Pigatto, L., Nha, I.-S., Hamel, J., Johnson, K., Kochhar, R. K., Nakamura, T., Orchiston, W., Pettersen, B. R., Schechner, S. J. \& Shi, Y. 2008, Division IX / Commission 41 / Working Group Historical /instruments. In van der Hucht, K. (ed.), Transactions of the IAU, Volume XXVIIA: Reports on Astronomy 2006-2009. Cambridge, Cambridge University Press. Pp. 423

Ratcliff, J. 2008, The Transit of Venus Enterprise in Victorian Britain. London, Pickering \& Chatto

Ruggles, C. L. N. \& Cotte, M. (eds.) 2010, Heritage Sites of Astronomy and Archaeoastronomy in the Context of the UNESCO World Heritage Convention: a Thematic Study. Paris, ICOMOSIAU [electronic edition; a printed edition was published in 2011]

Ruggles, C. \& Wolfschmidt, G. 2011, Division IX / Commission 41 / Working Group Astronomy and World Heritage. In Corbett. I. (ed.), Transactions of the IAU, Volume XXVIIIA: Reports on Astronomy 2009-2012. Cambridge, Cambridge University Press. Pp. 405-407

Ruggles, C., Kochhar, R., Nha, I. -S., Belmonte, J., Corbin, B., de Jong, T., Norris, R., Pigatto, L., Soma, M., Sterken, C. \& Sun, X. 2011, Commission 41. History of Astronomy. In Corbett, I. (ed.), Transactions of the IAU, Volume XXVIIIA: Reports on Astronomy 2009-2012. Cambridge, Cambridge University Press. Pp. 394-397

Schaefer, B.E. 2001, J. Hist. Astronomy, 32, 325

Schechner, S., Nakamura, T., Pigatto, L., Hamel, J., Johnson, K., Kochhar, R., Nha, I. -S., Orchiston, W., Pettersen, B. R. \& Shi, Y. 2011, Division IX / Commission 41 / Working Group Historical Instruments. In Corbett. I. (ed.), Transactions of the IAU, Volume XXVIIIA: Reports on Astronomy 2009-2012. Cambridge, Cambridge University Press. Pp. 400-402

Sellars, D. 2001, The Transit of Venus: The Quest to Find the True Distance of the Sun. Leeds, Maga Velda Press

Sheehan, B. \& Westfall, J. 2004, Transits of Venus. New York, Springer

Simaan, A., Blamont, J., Cannat, G., Delaye, Y., Laudon, M., Luminet, J. -P., Sellers, D. \& Roode, S. M. van 2003, Vénus Devant le Soleil. Comprendre et Observer un Phénomène Astronomique. Paris, Vuibert \& Adapt

Smith, J. 2005, The Struve Geodetic Arc. International Institution for History of Surveying \& Measurement. International Federation of Surveyors

Stephenson, F. R., Gurshtein, A., Dick, S. J., Orchiston, W., Dick, W., Kochhar, R., Nakamura, T., Nha, I.-S., Sullivan, W. T. \& Warner, B. 2003, Commission 41: History of Astronomy \& the Inter-Union Commission for History of Astronomy (ICHA). In Rickman, H. (ed.), IAU Reports on Astronomy, Volume XXVA. San Francisco, Astronomical Society of the Pacific. Pp. 441-454

Sterken, C., \& Aspaas, P. P. (eds.) 2013, Meeting Venus - a Collection of Papers Presented at the Venus Transit Conference. Troms 2012. Brussels, Vrije Universiteit

Sterken, C. \& Duerbeck, H. (eds.) 2005, Astronomical Heritages: Astronomical Archives and Historic Transits of Venus. Brussels, Vrije Universiteit

Sullivan III, W. T. 2005, The Early Years of Radio Astronomy. Reflections Fifty Years after Jansky's Discovery (Paperback edition). Cambridge, Cambridge University Press

Sullivan III, W. T. 2009, Cosmic Noise: A History of Early Radio Astronomy. Cambridge, Cambridge University Press 
Waluska, E. 2007, J. Astron. Hist. \& Heritage, 10, 79

Wielebinski, R., Kellermann, K. \& Orchiston, W. (eds.) 2007, The Early History of European Radio Astronomy. Special issue of Astronomische Nachrichten, 238(5), 375-446

Wolfschmidt, G. (ed.) 2009, Cultural Heritage of Astronomical Observatories: from Classical Astronomy to Modern Astrophysics. ICOMOS-Bässler-Verlag 